\title{
PROJECT ORGANIZATIONS AND SCHEDULES
}

\author{
Richard J. Briggs \\ Superconducting Super Collider Laboratory* \\ Project Management Division \\ 2550 Beckleymeade Avenue \\ Dallas, TX 75237
}

July 1990

\section{DISCLAIMER}

This report was prepared as an account of work sponsored by an agency of the United States Ther employees, makes any warranty, express or implied, or assumes any legal liability or responsibility for the accuracy, completeness, or usefulness of any information, apparatus, product, or process disclosed, or represents that its use would not infringe privately owned rights. Referprocess disclosed, or secific commercial product, process, or service by trade name, trademark, manufacturer, or otherwise does not necessarily constitute or imply its endorsement, recommanufacturer, or otherwhe United States Government or any agency thereof. The views and opinions of authors expressed herein do not necessarily state or reflect those of the United States Government or any agency thereof.

* Operated by Universitie: Research Association, Inc., for the U.S. Department of Energy under Contract No. DE-AC'02-89ER40486. 


\title{
Project Organizations and Schedules*
}

\author{
Richard J. Briggs \\ Superconducting Super Collider Laboratory ${ }^{\dagger}$ \\ 2550 Beckleymeade Avenue, Dallas, Texas 75237
}

\begin{abstract}
The Superconducting Super Collider Laboratory (SSCL) faces the challenge of simultaneously carrying out a large-scale construction project with demanding cost, schedule, and performance goals; and creating a scientific laboratory capable of exploiting this unique scientific instrument. This paper describes the status of the laboratory organization developed to achieve these goals, and the major near-term schedule objectives of the project.
\end{abstract}

\section{Organization}

The SSCL has grown rapidly during the first year of its existence. The laboratory staff started with a core group of less than 100 emplovees located in the Central Design Group in Berkeley, California, and grew to over 600 employees located in the temporary quarters in Dallas. Texas. The challenge faced by the laboratory is how to combine the execution of a large scale construction project-with demanding cost, schedule and performance goals-with the creation of a laboratory infrastructure that will support and promote creative science activities and its associated educational benefits. Models of other scientifically oriented megaprojects, such as those in NASA, combined with the successful approaches used in the past in high energy physics projects provide guidance, but it is clear that new ground is being broken by the SSC.

The most recent organization chart is shown in Figure 1. The roles and responsibilities of the kev leadership positions are as follows. The Director establishes the goals and policies for the laboratory, and he develops the strategic plan for the project and the laboratory in the context of the world high energy physics program. The Project Manager reports to the Director, and he is responsible for the execution of the construction project, consisting of the accelerator technical systems and the conventional facilities. The development and acquisition of the superconducting magnets, because

\footnotetext{
"Presented at the International Industrial Symposium on the Super Collider, Miami Beach, Florida, March 14-16, 1990.

'Operated by the Universities Research Association, Inc, for the U.S. Department of Energy under Coniract, No. DE-AC02-89ER40486.
} 


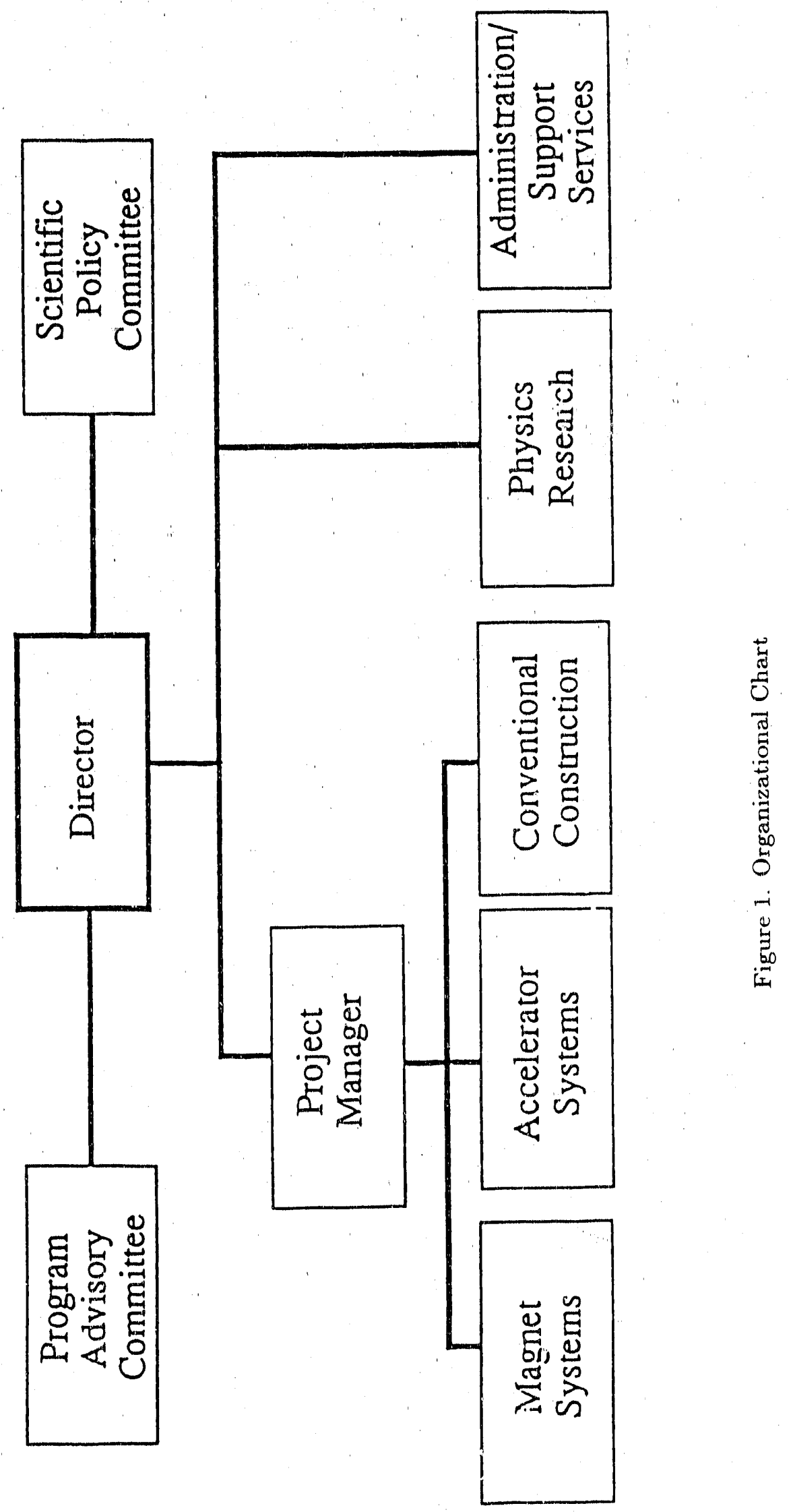


of the magnitude of this accelerator component task, is the responsibility of a separate division (Magnet Systems). All other technical systerns in the accelerator complex are the responsibility of the Accelerator Systems Division. The Conventional Construction Division is responsible for the conventional facilities, including the underground tunnels and the surface facilities.

A new feature of the present organization is the addition of a Technical Director supporting the Project Manager, as shown in more detail in Figure 2. The Technical Director, supported by system integration group leaders for the major portions of the accelerator, leads the physics design of the accelerator and has responsibility for all the technical requirements and interface definitions.

The Technical Services and Administrative Services Divisions provide support to the construction project, and they are also part of the laboratory infrastructure supporting scientific research. These scientific activities will, of course, become the mainstream of the laboratory when the construction is completed and the operating piase begins.

The Physics Research Division reports to the Director, sepurate from the construction project organization. The Physics Research Division is responsible for the detectors, and these components are designed and constructed by scientific collaborations involving many universities and other research organizations. The management and coordination of these collaborations is of a different character from the rest of the construction project, which is a more traditional project activity under the direct line authority of the SSCL project manager.

\section{Schedules}

The near-term priorities of the SSC project are:

1. Baseline cost/schedule/performance validation.

2. Development of industrial capability to produce large numbers of superconducting magnets.

3. System tests of a prototype collider segment by September 1992.

The development of the near-term schedule is driven by these priority items, which are critical to establish the readiness of the SSC project to move forward. The current definition of the baseline design of the SSC complex has been documented in a prelim. inary draft of the Site-Specific Conceptual Design, and a final version reflecting major design decisions is being prepared. Other papers at this symposium provide details of this design. The cost and schedule is also being finalized, and it will be subjected to a major review in early Summer 1990.

One major change from the earlier designs is the choice of aperture in the collider dipole magnets (CDM)-namely, $50 \mathrm{~mm}$ rather than $40 \mathrm{~mm}$. This change led to restructuring of the superconducting magnet development. Strong support from Fermilab, Brookhaven, and Lawrence Berkeley Laboratories will continue (Figure 3), with the industrial contractor working in partnership with the laboratories after the selection has been made (Figure 4). Assembly of about a dozen collider dipole magnets by the industrial contractor at Fermilab is part of the technology transfer plan. These magnets, assembled by the industrial team, will be used to form a segment of the collider system for system testing by Septomber 1992 (item 3 on the above list).

The first part of this "string test" will take place at a surface facility where five superconducting dipole magnets will be connecied together. The major goals of the string test are: 


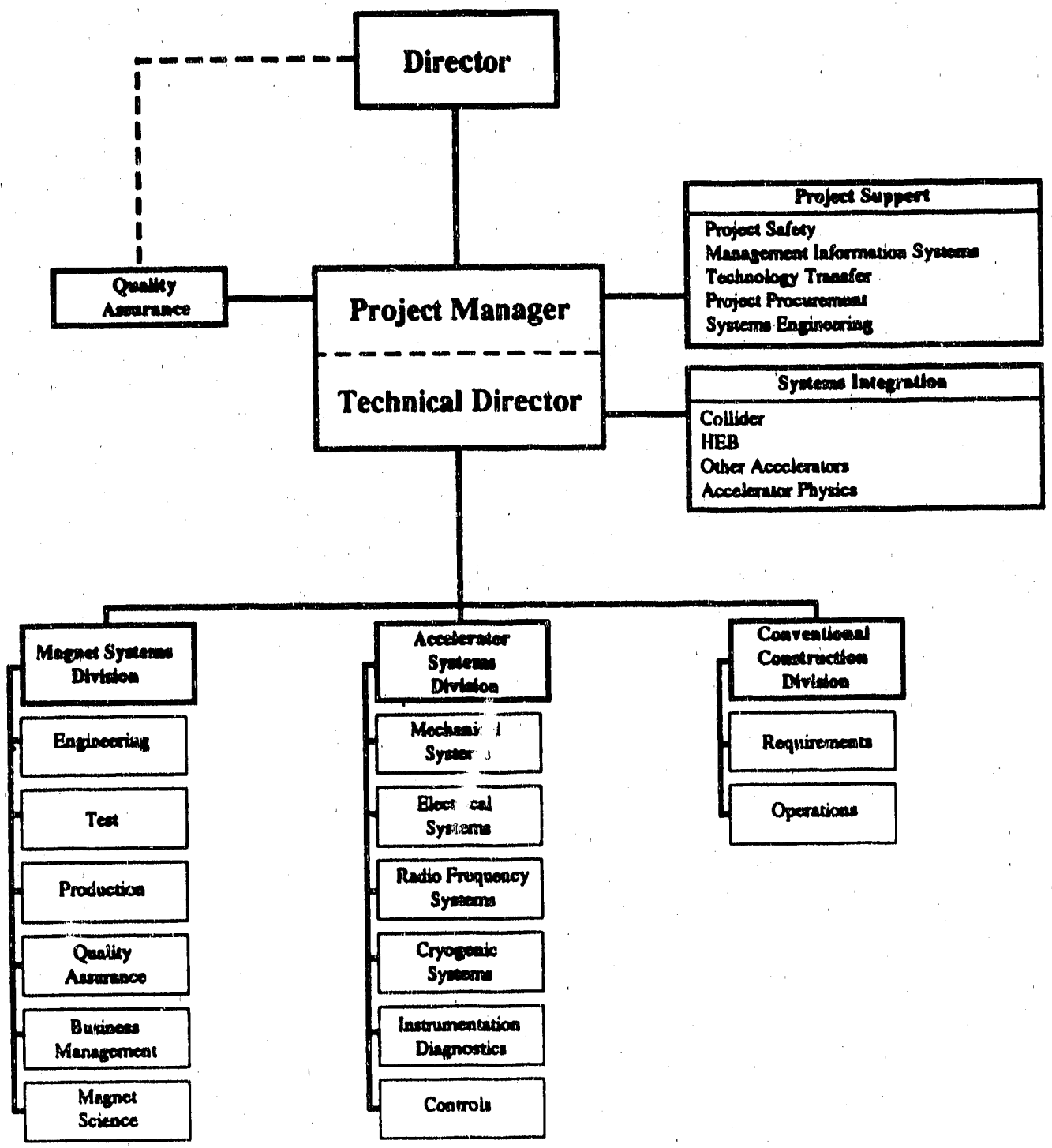

Figure 2. Technical Director Organization 


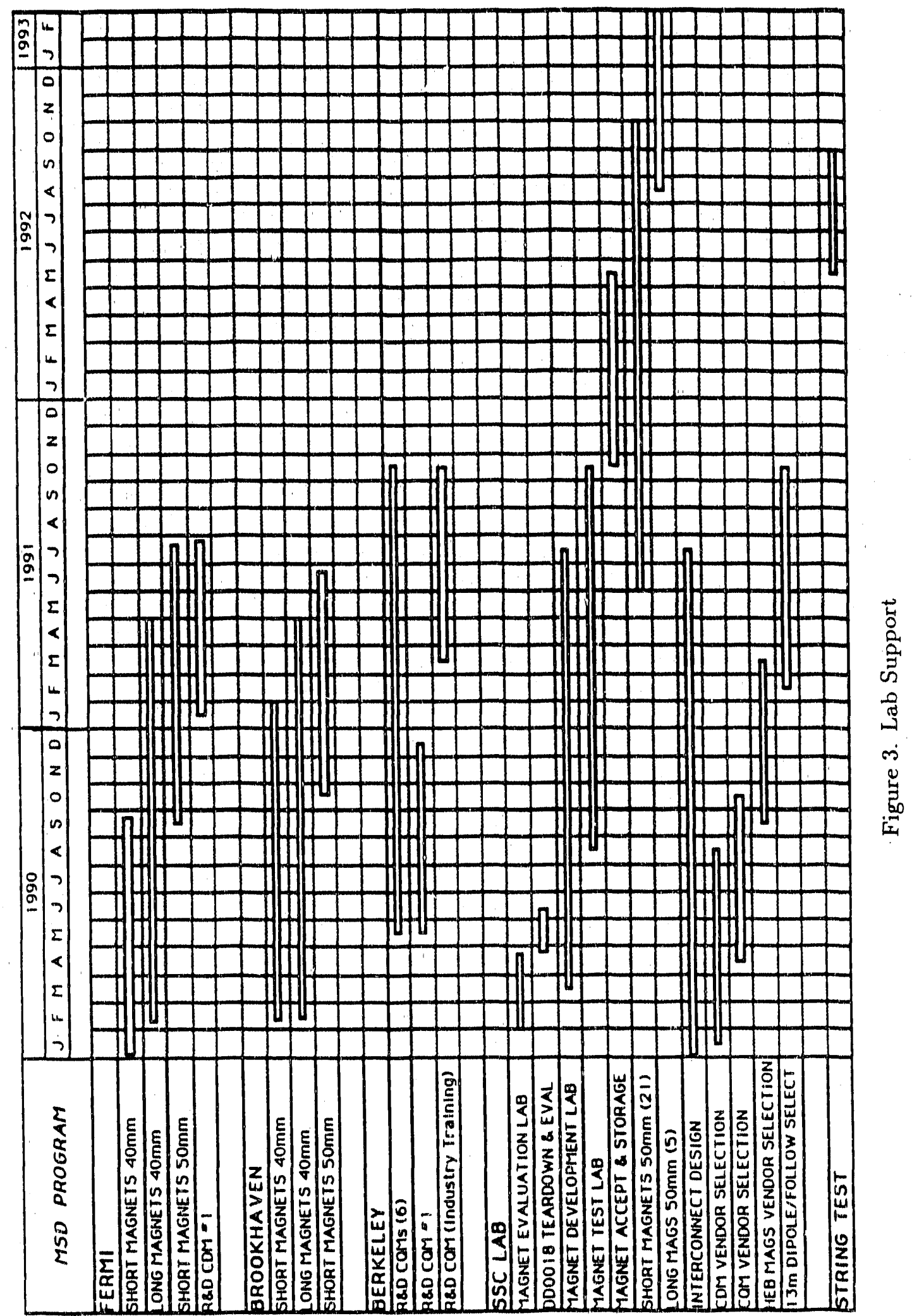




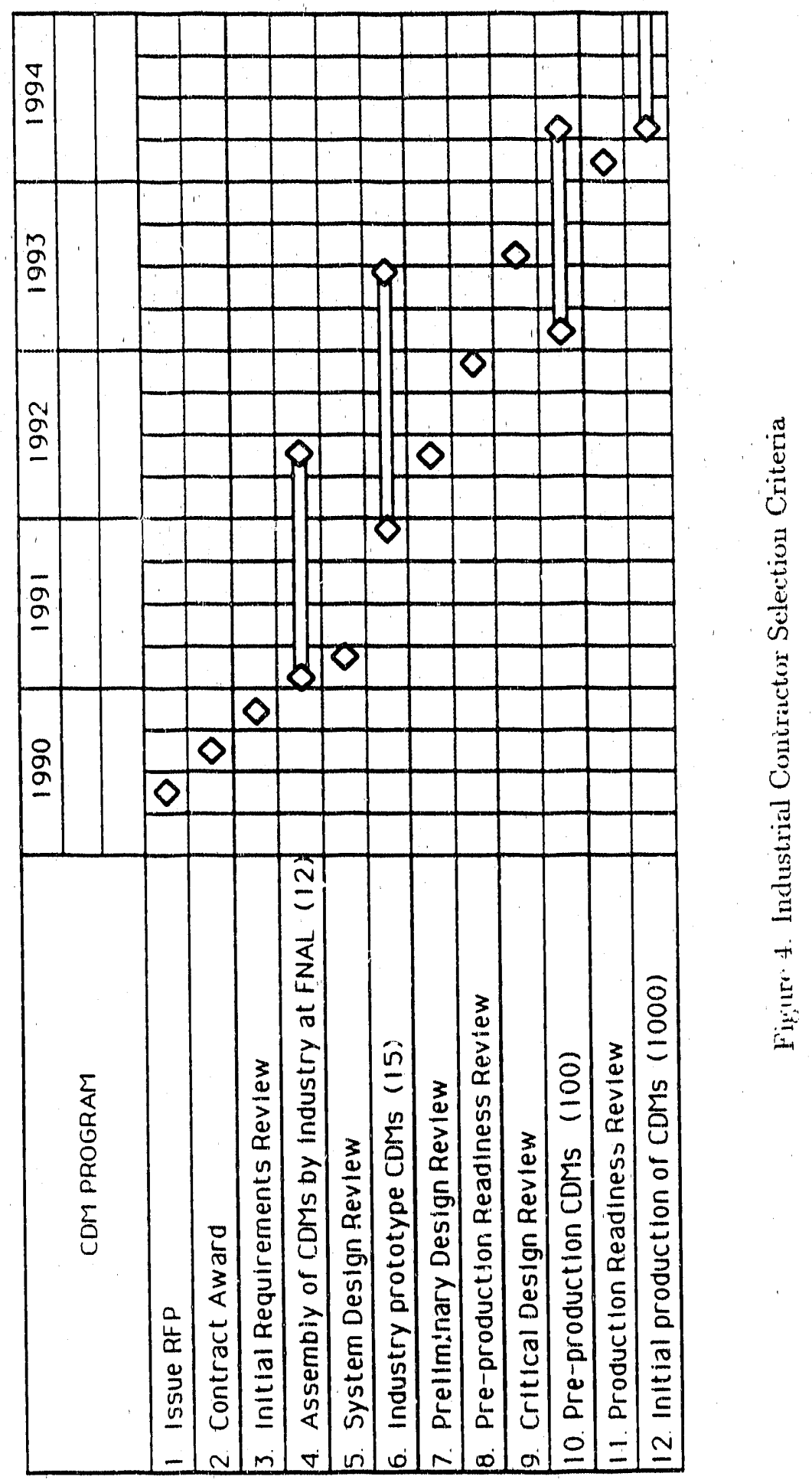


- The installation of the magnets to test the design of the magnet interconnects: electrical, cryogenic, and vacuum connections.

- The operation and integrity of the vacuum system.

- The ability to cool the string to liquid helium temperatures, verifying operation and control of the refrigerator system.

- The demonstration of the power supply, quench protection and controls systems, as well as the superconducting magnets, by ramping the string under conditions similar to those expected in operation.

These tests involve the first implementation of the major systems necessary to operate the collider and are the next important step in the SSCL program following successful tests of individual magnets. Following the surface facility tests, a similar test will be made below ground in a tunnel segment to test the operation of the support systems (cryogenics, electrical, and vacuum) in a realistic environment. The schedule of tasks involved in these system tests is shown in Figure 5. Results from these system tests are essential before the preproduction collider dipole manufacturing begins, and the production design of interconnections and spool pieces is finalized.

The top-level milestones over the full duration of the SSC construction project are shown in Figure 6. These milestones are preliminary versions; finalization of the baseline schedule will occur in late-Summer 1990 according to our present plan. 


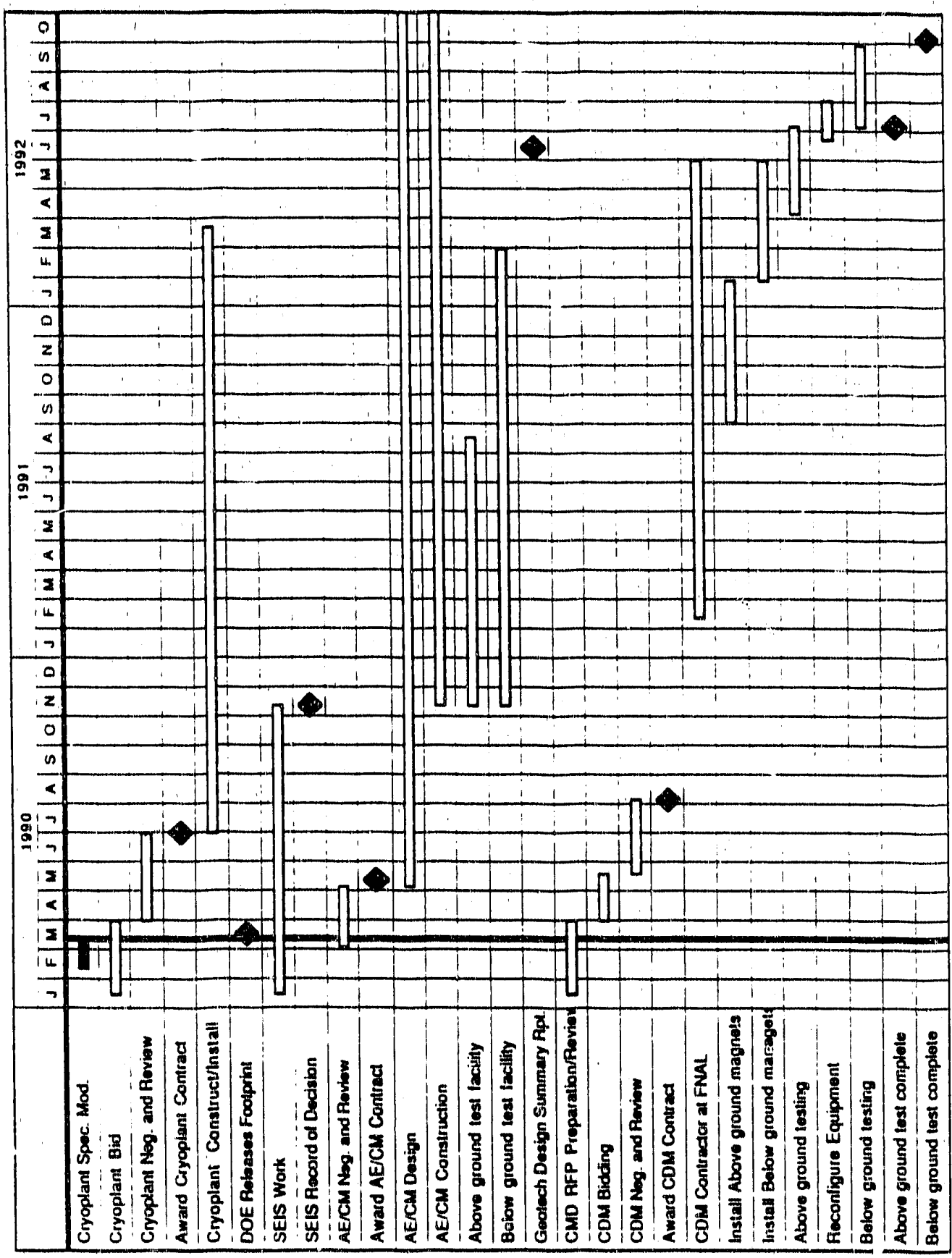

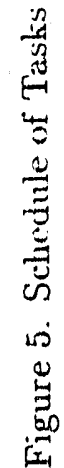


MÁNOR MULESTONES ROR SSC

Premiminary Date

AE/CM Awand

May 90

Baseline Validation Complexe

July 90

Collidex Dipole Magnet (CDM)

Aug. 90

Contract Award

Nov, 90

CDM Preliminary Design Review

July 92

Collider String Test

Sept 92

First Collider Sector - Start Installation of

Jan. 94

Major Components

Start CDM Production

April 94

Linac - Start Commissioning

Sept. 94

MEB - Start Commissioning

Oct. 95

HEB - Star Installation

Jan. 96

MEB - Test Beams Available

April 96

HEB - Stant Commissioning

Oct. 97

SSC - Start Commissioning

April 98

SSC - Beam to Experiments

Oct. 98

Figure 6. Top-Level Milestone Chart 

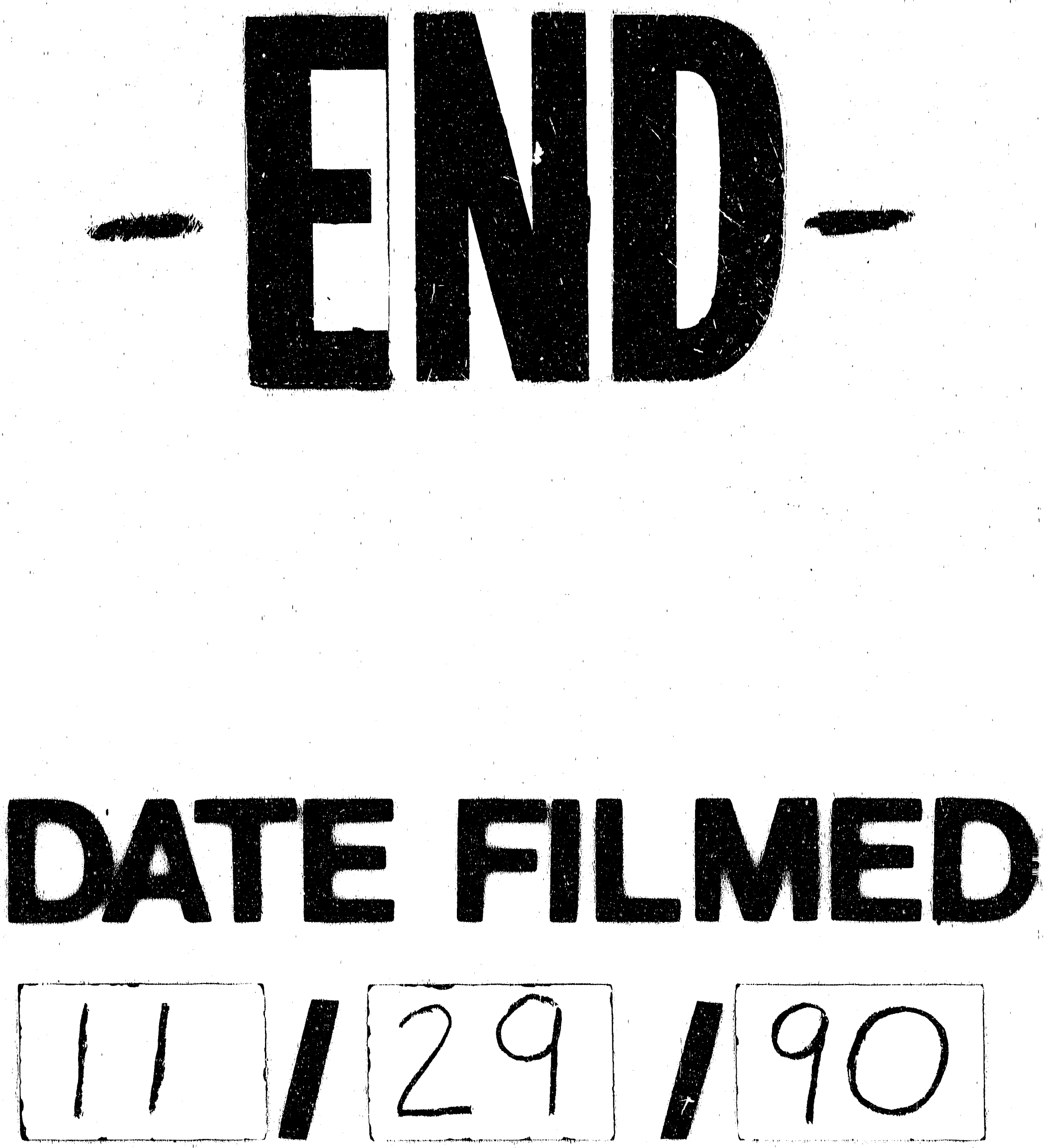
